\title{
LEARNING DESIGN, LEARNING ANALYTICS, AND LEARNING MANAGEMENT SYSTEMS
}

\author{
M. Godsk, J.B. Bennedsen, R.F. Hougaard \\ Aarhus University (DENMARK)
}

\begin{abstract}
This paper presents an educational development methodology currently deployed at the faculty of Science and Technology at Aarhus University for linking learning design, learning analytics, and LMS. The methodology describes (1) how a learning design is developed; (2) how it is implemented in the LMS including how data is collected, analysed, and presented to the educator throughout the module; and (3) how summative learning analytics informs the future learning design. The paper also presents our alternative "stealth" approach to learning design, where the ideas of learning design and learning design models are informally and/or indirectly presented to the educators.
\end{abstract}

\section{INTRODUCTION}

Learning design and learning analytics is gaining footing in higher education as a methodology for improving teaching and learning in a systematic and sustainable way based on pedagogical theory and insights into students' activity and achievements [1,2]. Though these two areas are interlinked, little work has been done to combine these, that is, to link learning analytics to learning design by using collected data to inform the learning design in a systematic way. Furthermore, the support for this link is often absent in standard learning management systems (LMS) and requires the educator to make sense of data that is not directly linked to a learning design.

\section{LEARNING DESIGN METHODOLOGY}

At the faculty of Science and Technology, we are currently implementing a learning design approach as a method to support the integration of technology in the teaching. Learning design can take many forms ranging from a highly structured teaching method, which engages teachers in learning design workshops facilitated by educational developers, to a more open-ended approach where teachers alone or assisted by educational developers design their teaching according to existing pedagogical models or concepts (Figure 1). Figure 1 illustrates how we at our faculty have used one underlying learning design model as the basis for both a highly structured approach called "ReTaught" and a more open-ended approach called "Learning Design by Stealth". These two approaches coexist in our development practice and are applied when best suited as determined by relevant barriers, such as the educators' time schedule, level of motivation, and ambition to integrate technology in his or her teaching.

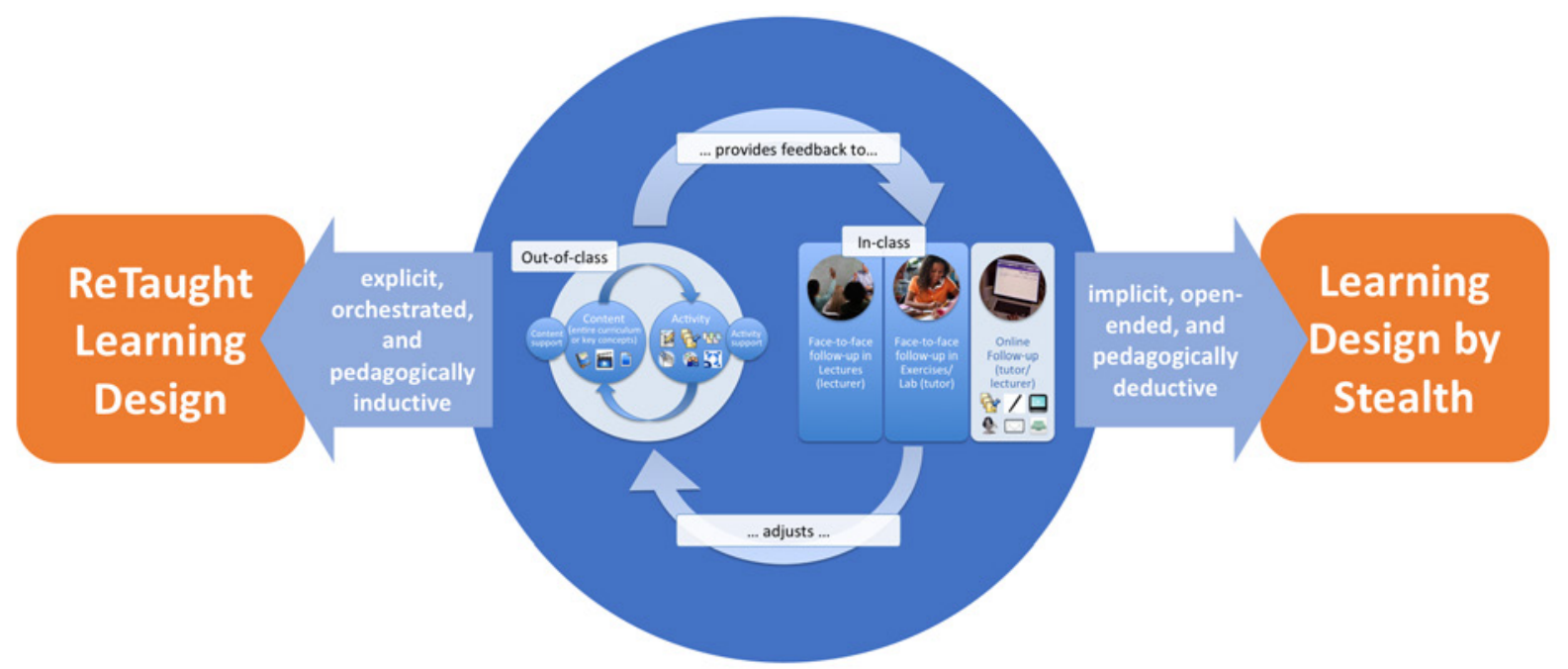

Figure 1. The dichotomy of the learning design methodology at AU ST. 


\section{RETAUGHT LEARNING DESIGN}

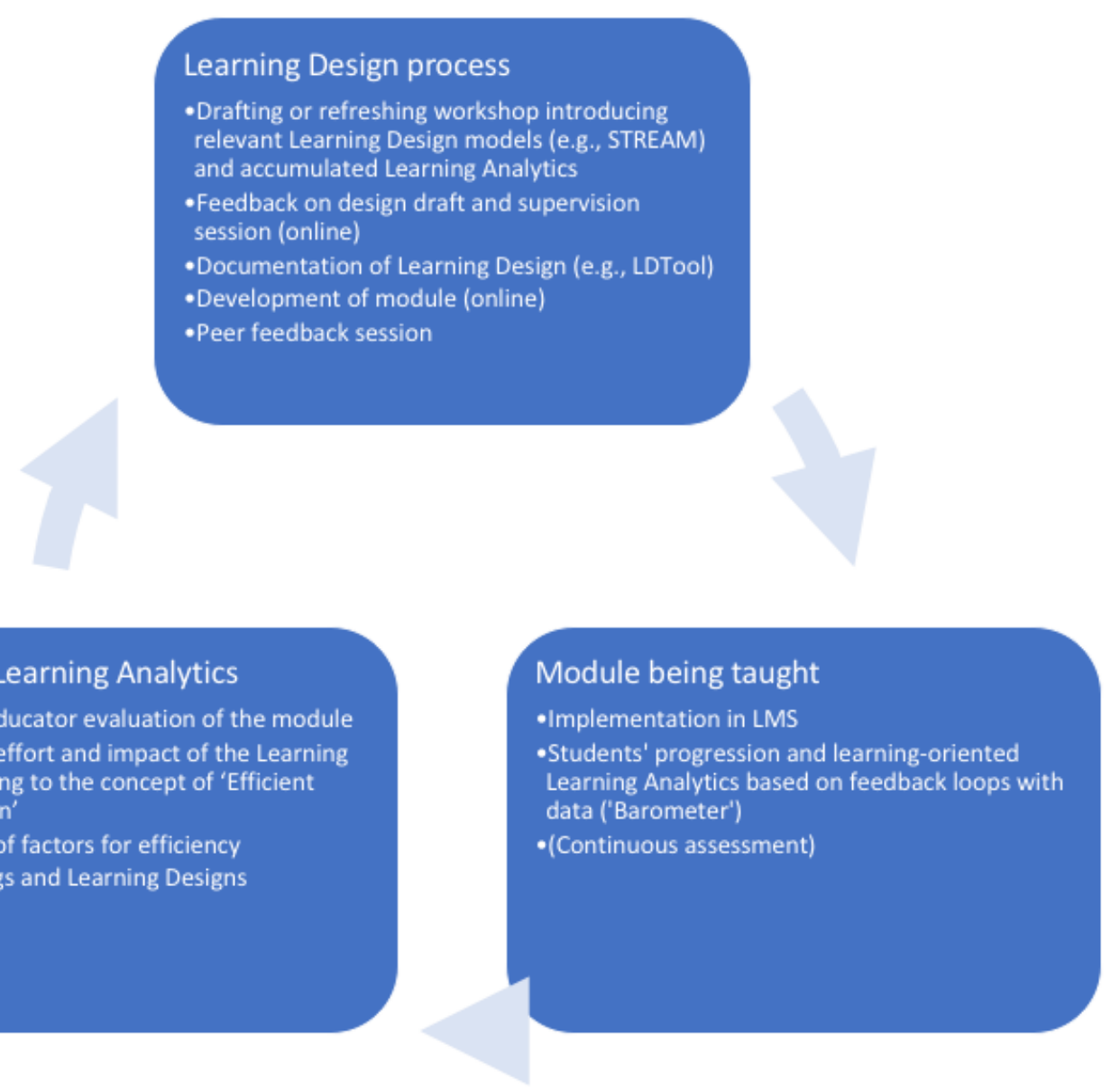

Summative Learning Analytics

-Student and educator evaluation of the module

-Assessing the effort and impact of the Learning

Design according to the concept of 'Efficient

Learning Design

-Identification of factors for efficiency

- Sharing findings and Learning Designs

\section{Module being taught}

-Implementation in LMS

-Students' progression and learning-oriented data ('Barometer')

-(Continuous assessment)

Figure 2. The "ReTaught" learning design process.

The ReTaught learning design process (Figure 2) starts with a comprehensive face-to-face educator workshop of typically $4-5$ hours run by educational developers. The educators are presented with the underlying ideas, models, and examples of learning designs. By means of Open University's 'Curriculum Feature cards' [3] the educators individually identify what they view as key qualities of teaching their specific module and inductively conceive their individual learning designs based on the presented models and examples. During the following three weeks, the educators draft their learning design, represent it by means of the LDTool [4], and share it with the educational developers for feedback. Based on individual supervision, the final learning design is developed and implemented in the LMS over a three-week period. A final peer feedback workshop of 2-3 hours is organised with the purpose of refining the designs and clarify any misunderstandings. After this, the module is delivered.

After the completion of the module, the students participate in an extended version of the institutional module evaluation and the educator participates in a survey. Furthermore, additional information about the learning design, grades, and time consumption is collected. The data forms the basis of a summative learning analysis conducted by the educational developers to analyse the efforts and impacts of the different learning designs and to identify factors that contribute to efficient learning designs [5]. Designs, results, and know-how is subsequently shared with other educators to inform new designs in later workshops and later revisions of existing designs. 


\subsection{Case 1: Civil engineering educators as learning designers}

A two-day workshop (14 hours in total, including breaks) for 31 civil engineering educators at AU ST was held in August 2018. The workshop was organized as a part of the annual department seminar and was supported by the degree programme director who also participated in the workshop. The workshop included short presentations including an introduction to learning design, presentations of a series of learning design cases and pedagogical models, and a presentation on technologysupported continuous assessment. In addition, time was allocated for educators to work on the development of learning designs for their own teaching. During the workshop, all participating educators managed to devise and/or develop components for their teaching so that today technology is an integrated part of their learning design in a manner based on one or more of the pedagogical models they were presented with. In addition, most educators began the actual implementation in the LMS. Hence, it was possible for merely two educational developers to support 31 educators with a pedagogically qualified technology enhancement of about 15 modules. In addition, there may be other and subsequent modules where the very same educators can reuse their newly acquired knowledge on technology in teaching and their related experiences.

\section{LEARNING DESIGN BY "STEALTH" AND SIMPLE LEARNING ANALYTICS}

It may not always be suitable or appropriate to engage educators in a learning design process as described above due to, e.g., practical or educator intrinsic barriers. Thus, an alternative approach is used in which educators are indirectly introduced to learning design through learning design models, key features from learning design models, and/or other learning design features that address an urgent technical, pedagogical, or media-related need in his or her teaching practice.

The two cases below illustrate how educators with urgent needs and/or technical/media ambitions and without an explicit pedagogical agenda are developing solutions that are informed by and/or empowered by learning design nonetheless. When suitable and appropriate, the next step could be to involve the educators in a more comprehensive learning design process as described in the previous section.

\subsection{Case 2: Calculus 2 in 2014}

The Calculus 2 educator wanted to replace all lectures with video recordings but was not sure how to integrate this in his teaching practice. The STREAM model [6] provides suggestions on how video material can be used actively in teaching practices by means of loops of content and activity. Therefore, the educator was introduced to the idea of splitting his video material into smaller parts combined with quizzes and how this could be implemented in the LMS by means of a learning path. The educator was not directly presented to the STREAM model or its underlying pedagogical principles of feedback loops and active learning, but a connection between his teaching practice and pedagogical theories and learning design has now been made.

Since the educator - like many other educators at AU ST - was already using clickers in his lectures and, moreover, was aware of the pedagogical advantages this technology provides, it was obvious that this could be "translated" into an online learning environment with MCQs embedded in the various learning modules. In this way, the educator would still have knowledge of the level of student progression and would be able to follow up on the topics that caused problems. The solution was to have educators and a designated "e-instructor" go through the students' answers and additional reflections on a weekly basis via the grade centre in the LMS. Based on that they would create follow-up videos or other material that addressed the topics that the students had trouble understanding. Figure 3 illustrates an example of the results of the two MCQs available to the educator via the LMS. From this, the educator could conclude that, for example, $23 \%$ and $17 \%$ of the students answered incorrectly on the first two questions on double integrals. Furthermore, since more than about $90 \%$ of the students answered correctly on the other MCQ questions in the learning module, it indicates that their academic performance is too low within this topic and that measures need to be taken. 


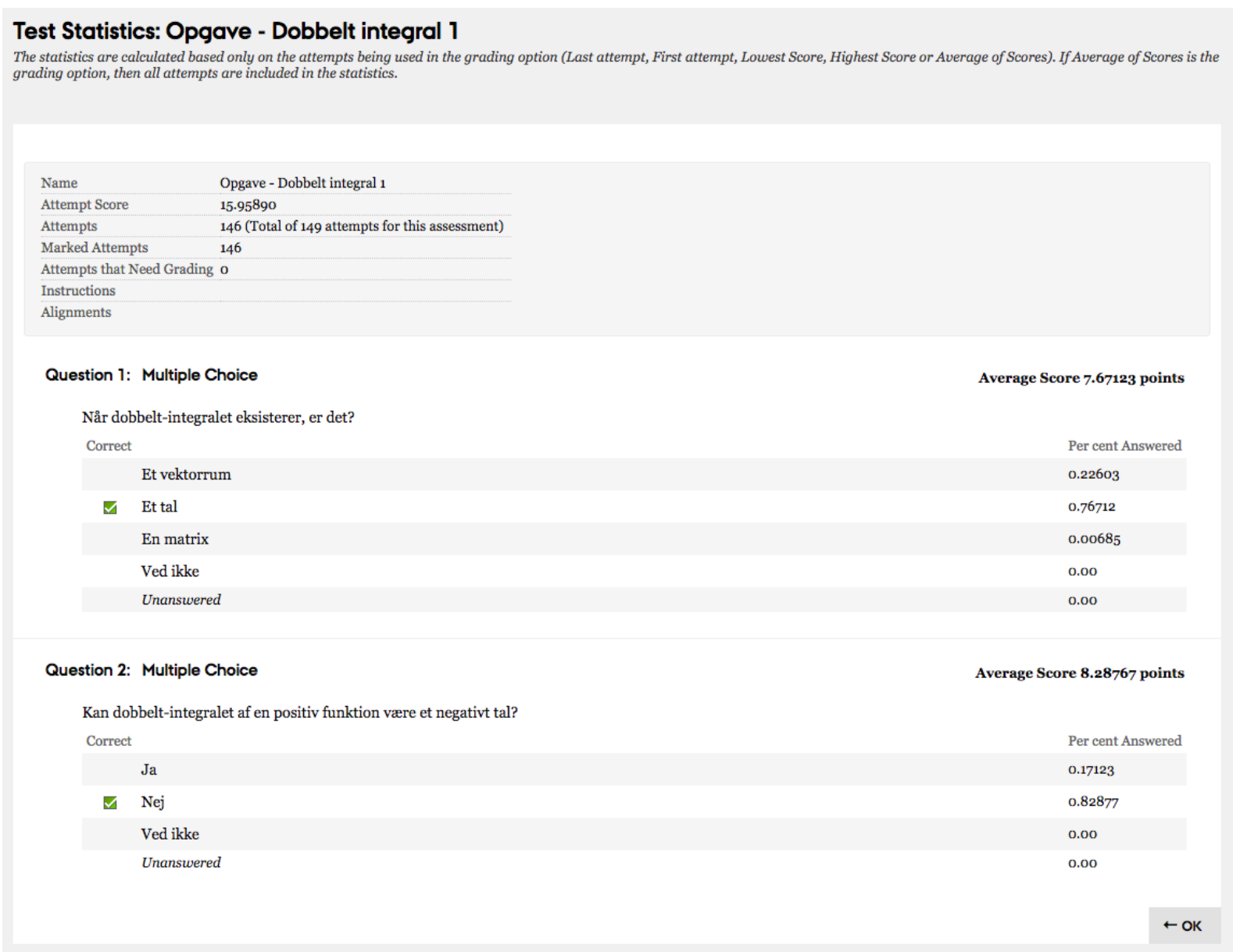

Figure 3. Using MCQs for analysing academic performance.

In this way, the MCQs worked as indicators of students' activity and especially as indicators of academic performance, which the educator could then act on. Because of the size of the class, the educator decided to give collective feedback. However, since the data on every single student was already available, individual feedback could also have been an option.

In connection with the students' learning, their level of satisfaction and flexibility was slightly improved compared to previous years. For example, $50 \%$ of the students responded that they preferred the transformed format without lectures opposed to the $31 \%$ that preferred the traditional format. The educator also reported great satisfaction with the process despite a larger consumption of time than normally. He stated in an interview:

'It has been really fun to me. And I think it has worked well. I can feel that I've personally developed through this. I've learnt some things on the personal level, which I highly appreciate' (Calculus 2 educator).

\subsection{Case 3: General Chemistry in 2016}

The General Chemistry educator had identified that a specific concept, chemical equilibrium, and its related tasks, calculation of $\mathrm{pH}$ in solutions, were particularly difficult for the students to understand in the course and at later stages of the chemistry programme.

'...many, many students provide wrong answers at their examination and have had many difficulties grasping it... So, this was an attempt to help them because they should become as good to this as the other parts of the curriculum' (General Chemistry educator).

Without verbalising the pedagogical principle, the educator was introduced to the concept of activating course content though online tasks and the possibility of providing automated feedback via the LMS test tool. In addition, the possibility for the educator to gain insight into students' difficulties and current understanding via their performance on individual test questions were emphasised. Based on this, the 
educator intended to develop an optional online self-paced learning environment where students could train the calculation skills related to the topic. Besides this, the LMS was only used for distributing materials and practical information related to the course both before and after the intervention.

The resulting learning design contained a webcast video and 22 quizzes. The short webcast video covered specific chemical concepts and mathematical procedures related to the $\mathrm{pH}$ calculation tasks. With the assistance of a tutor, existing complex calculation tasks were divided into several smaller tasks, representing individual steps involving chemical concepts or mathematical procedures inherent in the problem-solving process, and transformed into multiple choice test questions. Based on this, online tests were developed in the LMS by the educational development team. Large effort was put into writing specific feedback to wrong answers so that students were guided towards finding the correct solution themselves instead of merely providing the correct answer.

The rationale behind the chunking of the problem-solving tasks into several steps is that in this way, the automated feedback from the LMS will inform the students about which specific misconceptions they suffer and guide them towards applying the correct concept or procedure. Similarly, LMS statistics on the number of attempts necessary for each student to solve a specific step in the procedure will provide detailed information to the educator about students' mastery of specific concepts and procedures. In this way, putative misconceptions and difficulties can be addressed at later stages in the course.

During the in-class lecture where the topic was covered the online materials were presented as an optional resource for the students to use out-of-class. Although it was optional, $63 \%$ of the students watched the video and $51 \%$ participated in the online test. Of these $82 \%$ reported that the materials to some/high/very high extent ( $60 \%$ to a high/very high extent) helped them understand the topic. In addition, $66 \%$ of the students reported that they used the materials for deep learning purposes. This suggests that the materials were perceived as a useful learning resource by the students.

The extra effort spent on production of the online materials by the educator and tutor was estimated to a total of 55 hours. During the first run of the online design, the educator did not monitor students' performance in the test. Nevertheless, the educator perceived the productions of material as 'easy' and the outcome as highly positive.

'It's been easy... That you can delegate parts of the understanding to not only occur during a lecture but that you can refer [to the online material]. They can review a video with almost the same lecture, they can train the different parts by means of the exercises. What this does is good, I think it is a good idea, and that is not difficult- it is easy' (General Chemistry educator).

In this case, it appears that transforming existing teaching materials (examples and problem-solving tasks) into interactive digital materials in the LMS can be done with a favourable cost-benefit balance and may offer significant advantages in relation to supporting students' learning.

'I think I will suggest that some of these things were expanded to also cover other parts of the curriculum' (General chemistry educator)

\section{CONCLUSIONS AND FUTURE WORK}

The paper concludes that learning design has a potential for supporting educational development both explicitly — as in 'ReTaught' — and implicitly — as in Learning Design by Stealth. Our results suggest that a rather simple conversion of existing teaching materials to online materials combined with online activities in the LMS has the potential to provide valuable information about student performance to both students and educators. This was valued as useful by both students and educators. In addition, summative learning analytics can be used to improve future learning designs and module deliveries, and simple learning analytics can be used to inform the teaching on a just-in-time basis. Nevertheless, there is still room for a further development of the learning analytics provided to the educators during module deliveries. A so-called 'Barometer' is currently being developed in the Grade Centre in Blackboard Learn for monitoring four indicators: 1) students' online activity, 2) online interaction, 3) academic performance (e.g., quiz scores), and 4) the utility of the LMS in terms of diversity of tools used and time flexibility.

\section{REFERENCES}

[1] Conole, G. (2013). "Designing for learning in an open world". New York: Springer. 
[2] Ferguson, R. (2012). "Learning analytics: drivers, developments and challenges". International Journal of Technology Enhanced Learning, 4(5-6), 304-317.

[3] The Open University (2018). Learning Design Downloads. Retrieved from http://www.open.ac.uk/iet/learning-design/downloads.

[4] University of Wollongong (2018). Home - LDTool. Retrieved from http://needle.uow.edu.au/ldt/

[5] Godsk, M. (2018). Improving STEM Undergraduate Education with Efficient Learning Design. EdD thesis. The Open University.

[6] Godsk, M. (2013). "STREAM: a Flexible Model for Transforming Higher Science Education into Blended and Online Learning". World Conference on E-Learning in Corporate, Government, Healthcare, and Higher Education, 1, 722-728.

[7] Novak, G, Patterson, E.T., Gavrin, A.D., and Christian, W. (1999). Just-In-Time Teaching: Blending Active Learning with Web Technology, Upper Saddle River, NJ: Prentice Hall 